\title{
Changing trends with respect to standard of methodological reporting and type of research published in a pharmacology journal over a decade: a descriptive study
}

\author{
Mangala Bhaskar Murthy ${ }^{1 *}$, Bhaskar Krishnamurthy Murthy ${ }^{2}$, \\ Shreyas Ramachandra Burute ${ }^{1}$, Praveenkumar T. Patil ${ }^{3}$, Sunita J. Ramanand ${ }^{1}$
}

${ }^{1}$ Department of Pharmacology, GMC, Miraj, India

${ }^{2}$ Department of Obstetrics and Gynaecology, GMC, Miraj, India

${ }^{3}$ Department of Pharmacology, GMC, Dhule, India

Received: 18 April 2016

Accepted: 03 June 2016

\section{*Correspondence to:}

Dr. Mangala Bhaskar Murthy, Email: mangala.bhaskar@ gmail.com

Copyright: (C) the author(s), publisher and licensee Medip Academy. This is an openaccess article distributed under the terms of the Creative Commons Attribution NonCommercial License, which permits unrestricted noncommercial use, distribution, and reproduction in any medium, provided the original work is properly cited.

\begin{abstract}
Background: Criticisms against Indian research include features like redundant research topic, low quality methodological reporting leading to less credible results and poor statistical rigor to mention a few. A 'publication audit' of previously published studies in terms of research trend and standards of methodological reporting will help us to identify problem areas so that rectifications if required may be undertaken.

Methods: This was a descriptive study conducted on the research articles published in a journal of Pharmacology during years 2005 and 2015. Comparison was done to see any differences in type of studies published and also to assess their standards of methodological reporting on the basis of a predesigned checklist. Descriptive statistics were used to analyse data.

Results: The proportion of full length research articles published increased from $30.97 \%$ in the year 2005 to $46.58 \%$ in the year 2015 , the number of studies involving human beings increased to $26.86 \%$ (as compared to $8 \%$ in 2005), studies using drugs as active principle doubled in 2015 as compared to 2005. Focus on area of research shifted from inflammation and wound healing in 2005 to central nervous system in 2015 . With respect to standard of reporting, albeit some improvement in the studies published in 2015, some missing links still exist.

Conclusions: There is scope for improvement in terms of report of study designs, justification of sample size and adherence to CONSORT (Consolidated statement for reporting randomized controlled trails) statement while reporting results of randomised controlled trials.
\end{abstract}

Keywords: Research articles, Quality of studies, Randomized controlled trials, CONSORT

\section{INTRODUCTION}

It is indeed shocking that research originating from India contributes to a small minority of research published worldwide. Criticisms against Indian research include features like redundant research topic, low quality methodological reporting leading to less credible results and poor statistical rigor to mention a few. ${ }^{1-4}$ Despite these limitations, most researchers resort to National journals in their fields to assist them in finding topics of their dissertation or research studies. While it is important to read such journals to keep abreast the advancements in knowledge, it is equally important to have a reality check with respect to methodological reporting standards of published studies at repeated intervals to see how far we have managed to overcome the aforementioned criticisms. Pharmacology is an evergreen subject to researchers and lot of changes can happen over a decade with respect to both type of published research and their quality of reporting. Indian journal of pharmacology is a leading indexed journal in the field of pharmacology with renowned editorial board, distinguished reviewers and authors around the globe. Thus, the purpose of the study was to assess any changing trends in type and quality of research published in a journal of pharmacology from 2005 to 2015 . This will not only help us in identifying the 
current research trends but will also provide us with an ascertainment of standard of methodological reporting of research in the form of a 'publication audit' so that problem areas may be identified and rectifications if required may be undertaken.

\section{METHODS}

This was a descriptive study conducted to compare the research articles published in the Indian journal of pharmacology in 2005 and 2015.

All research articles published in the Indian journal of Pharmacology during years 2005 and 2015 were included in the study. Original research presented in the form of short communications, letters to the editor were excluded from the study as word limits imposed on them could bias the quality check criteria used to assess the study. In-vitro studies were excluded from the study as many of the assessed criteria like study design are different from invivo studies and are not as rigorous for such protocols as compared to whole animal and human studies while the in-vitro studies involving tissue cultures, stem cells have different set of ethical issues unique to them. This makes in-vitro studies incomparable with others on the same scale and hence was excluded from the study.

Comparison was done to see any change in trend of publication with respect to type of studies published and also to assess their standards of methodological reporting.

For the sake of comparisons with respect to changing trends in the types of published research, studies published during the years 2005 and 2015 were classified on the basis of;

- Category under which the article was published. (Full length research article or others such as review articles, case reports, letter to the editor etc.) Proportion of original full length research articles and other articles published during the above years were also calculated).

- $\quad$ Subjects of research (whole animals, human studies).

- Origin of active principle used for research [research involving drugs and/or nutritional supplements, active chemicals not used as drugs, plant products and others not involving any active principle like educational research, drug utilization studies, surveys, qualitative or knowledge, attitude and practices (KAP) studies].

- Area of research (research related to area of pharmacology like general pharmacology involving toxicity studies, pharmacokinetic studies or systemic pharmacology involving research on gastrointestinal system, cardiovascular system, wound healing and inflammation and others).

Once classified in this manner, data was used for comparison to find change in publication trend with respect to types of studies published.
In order to compare the standard of methodological reporting of published studies, predesigned checklist of 8 criteria was used after pilot testing it on ten research studies published elsewhere. The criteria of checklist included: clear mention of each of the following: objectives, clearance from ethics committee, study design (if yes which?), sample size, justification for the size of sample used, statistical test, name of test if applied, statistical inference based on $\mathrm{p}$ value/confidence interval/both and declaration of conflict of interest.

A subgroup analysis of all randomized control trials was done as additional points need to be considered to assess the quality of these trials. This included additional checklist of 7 points: title clearly states that it is a randomized controlled trial, method of randomization, allocation concealment if done, method of concealment, weather blinding was done, CONSORT flow chart for patient accountability during the trial and registration of trial in a trial registry.

The extent to which the studies complied with the above checklist criteria was assessed. Comparison of research studies published in 2005 and 2015 with respect to adherence to the same criteria was done.

\section{Statistical analysis}

Descriptive statistics were used to quantify changing trend as well as to assess the standard of methodological reporting.

\section{RESULTS}

There were 113 publications in the year 2005 and 161 in the year 2016 under different categories out of which, 25 full length research papers from 2005 and 67 from 2015 met the inclusion criteria and were included in the study.

The first objective of the study was to compare the publications of the two years with respect to any change in trend and the following aspects were observed:

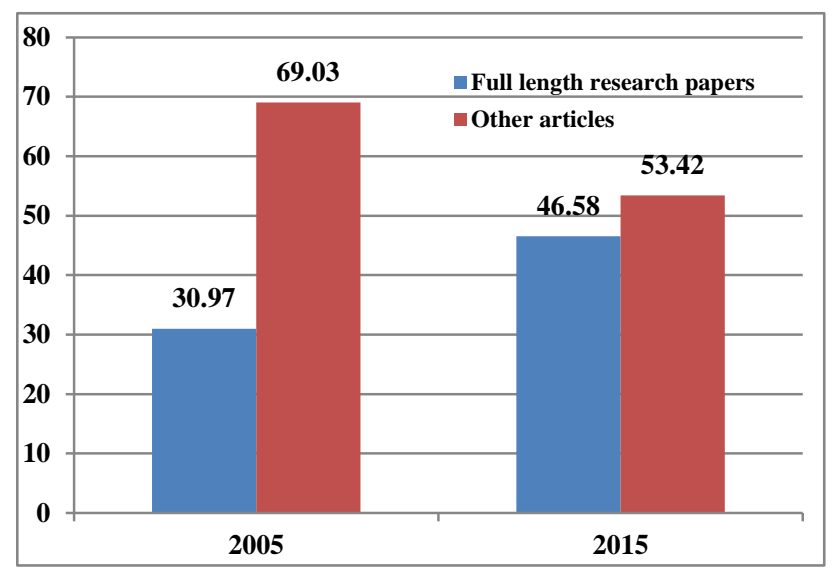

Figure 1: Comparison of proportion of research and non- research articles published. 
As seen from Figure 1, the proportion of full length research articles published increased from $30.97 \%$ in the year 2005 to $46.58 \%$ in the year 2015. Majority of publications in the year $2005(88 \%)$ and $2015(55.22 \%)$ comprised of animal studies. In 2015, there was not only a definite increase in the number of studies involving human beings to $26.86 \%$ (as compared to $8 \%$ in 2005), but there was also an increase in the variety of other studies like surveys, drug utilization studies and knowledge attitude and practices (KAP) studies and studies on different educational methods which amounted to $12 \%$ of published studies (Table 1). As seen in Table 2, active principles used for research in the studies published in 2005 were basically plant products in $64 \%$ of studies while this reduced to $37.31 \%$ in 2015 . Studies using drugs as active principle doubled in 2015 as compared to 2005 . (43.28\% in 2015 versus. $20 \%$ in 2005.) With respect to the area of research, focus shifted from inflammation and wound healing which contributed to $20 \%$ of studies published in 2005 making it the most common area of research thereof to central nervous system in 2015. Next common areas included cardiovascular system, general toxicity studies and central nervous system in 2005 while it was endocrine and gastrointestinal system in 2015 apart from others like educational research, drug utilization studies, surveys and KAP studies (Table 3).

Table 1: Comparison of research publications in 2005 and 2015 with respect to subjects of research.

\begin{tabular}{|lll|}
\hline Subjects of research & $\mathbf{2 0 0 5}$ & $\mathbf{2 0 1 5}$ \\
\hline Animals & $22(88 \%)$ & $37(55.22 \%)$ \\
\hline Human beings & $2(8 \%)$ & $18(26.86 \%)$ \\
\hline $\begin{array}{l}\text { Others types including } \\
\text { surveys, knowledge, } \\
\text { attitude practice studies, } \\
\text { educational research }\end{array}$ & $1(4 \%)$ & $12(17.92 \%)$ \\
\hline Total & $\mathbf{2 5 ( 1 0 0 \% )}$ & $\mathbf{6 7 ( 1 0 0 \% )}$ \\
\hline
\end{tabular}

Table 2: Comparison of research publications in 2005 and 2015 with respect to active principles used for research.

\begin{tabular}{|lll|}
\hline Active principle used & $\mathbf{2 0 0 5}$ & $\mathbf{2 0 1 5}$ \\
\hline Plant products & $16(64 \%)$ & $25(37.31 \%)$ \\
\hline Drugs/vitamins & $5(20 \%)$ & $29(43.28 \%)$ \\
\hline $\begin{array}{l}\text { Pure chemicals not } \\
\text { classified as drugs }\end{array}$ & $3(12 \%)$ & $1(1.49 \%)$ \\
\hline $\begin{array}{l}\text { Studies not utilizing any } \\
\text { active principles } \\
\text { (others- educational } \\
\text { research, KAP studies } \\
\text { and surveys) }\end{array}$ & $1(4 \%)$ & $12(17.91 \%)$ \\
\hline Total & $\mathbf{2 5 ( 1 0 0 \% )}$ & $\mathbf{6 7}(\mathbf{1 0 0 \% )}$ \\
\hline
\end{tabular}

The second objective was to compare the research published in the above two years with respect to standard of reporting the key methodological aspects of research. The following aspects were observed.

Table 3: Comparison of research publications in 2005 and 2015 with respect to area of pharmacology to which research was related.

\begin{tabular}{|lll|}
\hline Research area & 2005 & 2015 \\
\hline General pharmacology & & \\
\hline General toxicity studies & $3(12 \%)$ & $1(1.49 \%)$ \\
\hline Pharmacokinetic studies & $1(4 \%)$ & 0 \\
\hline Systemic pharmacology & & \\
\hline Cardiovascular system & $3(12 \%)$ & $4(5.97 \%)$ \\
\hline Central nervous system & $3(12 \%)$ & $18(26.86 \%)$ \\
\hline Renal system & 0 & $4(5.97 \%)$ \\
\hline Respiratory system & $1(4 \%)$ & $1(1.49 \%)$ \\
\hline Musculoskeletal system & 0 & $3(4.47 \%)$ \\
\hline Endocrine & $1(4 \%)$ & $7(10.44 \%)$ \\
\hline Chemotherapy & $3(12 \%)$ & $4(5.97 \%)$ \\
\hline Gastrointestinal system & $2(8 \%)$ & $6(8.95 \%)$ \\
\hline Ocular & 0 & $1(1.49 \%)$ \\
\hline Vitamins & $1(4 \%)$ & 0 \\
\hline Vaccines/sera & 0 & $1(1.49 \%)$ \\
\hline $\begin{array}{l}\text { Autacoids/inflammation } \\
\text { and wound healing }\end{array}$ & $5(20 \%)$ & $4(5.97 \%)$ \\
\hline Immunomodulators & $1(4 \%)$ & $1(1.49 \%)$ \\
\hline Others: educational & $1(4 \%)$ & $12(17.91 \%)$ \\
\hline Total & $\mathbf{2 5 ( 1 0 0 \% )}$ & $\mathbf{6 7}(\mathbf{1 0 0 \%})$ \\
\hline
\end{tabular}

Table 4: Comparison of standard of methodological reporting of trials.

\begin{tabular}{|lll|}
\hline $\begin{array}{l}\text { Parameters assessing } \\
\text { completeness of a study } \\
\text { report }\end{array}$ & $\begin{array}{l}\mathbf{2 0 0 5} \\
\mathbf{n 1 = 2 5}\end{array}$ & $\begin{array}{l}\mathbf{2 0 1 5} \\
\mathbf{n} 2=67\end{array}$ \\
\hline $\begin{array}{l}\text { Objectives clearly defined } \\
\text { Clearance from respective } \\
\text { ethics committee }\end{array}$ & $22(100 \%)$ & $67(100 \%)$ \\
\hline Study design clearly stated & $6(24 \%)$ & $58(86.56 \%)$ \\
\hline Sample size mentioned & $23(92 \%)$ & $66(92.68 \%)$ \\
\hline $\begin{array}{l}\text { Justification for sample size } \\
\text { provided }\end{array}$ & 0 & $3(4.47)$ \\
\hline Tests used for statistical analysis & \\
\hline ANOVA & 19 & 28 \\
\hline T test & 0 & 7 \\
\hline Chi-square test & 0 & 6 \\
\hline Others & 4 & 12 \\
\hline Multiple tests & $24(96 \%)$ & $59(88.65 \%)$ \\
\hline $\begin{array}{l}\text { Total number of studies } \\
\text { using inferential statistics to } \\
\text { draw inferences }\end{array}$ & & \\
\hline Statistical inference drawn on the basis of \\
\hline Value & $24(96 \%)$ & $47(70.14 \%)$ \\
\hline $\begin{array}{l}\text { P value and confidence } \\
\text { interval }\end{array}$ & 0 & $4(5.97 \%)$ \\
\hline Not mentioned & $1(4 \%)$ & $8(11.94 \%)$ \\
\hline $\begin{array}{l}\text { Declaration of conflict of } \\
\text { interest }\end{array}$ & $25(100 \%)$ & $66(98.93 \%)$ \\
\hline
\end{tabular}


As seen from Table 4, all the studies published had clearly defined objectives for the study. $88 \%$ studies from the year 2005 while $86.56 \%$ studies in the year 2015 mentioned about having obtained requisite approval from respective ethics committees (animal ethics committee/ institutional ethics committee). Study design was clearly stated in a higher proportion of studies published in 2015 $(62.68 \%)$ as compared to 2005 (24\%). Sample size was either mentioned in the methodology section or tables in $92 \%$ of the studies in 2005 while this increased to $98.50 \%$ in 2015. A distinct observation was that the justification for sample size used was not provided in any of the studies in 2005 while the sample size used was justified in $4.47 \%$ in 2015 . Total number of studies using inferential statistics actually reduced from $96 \%$ in 2005 to $88.65 \%$ in 2015. Anova followed by post-hoc tests was the commonest test used in both the years followed by paired and unpaired t test and chi square test in 2015. More number of studies used multiple tests in 2015 as compared to $2005 .^{4,12}$ In most of the studies that used inferential statistics, statistical significance was based on $\mathrm{p}$ value during both the years. Yet, $11.94 \%$ of studies in 2015 supported their results by both $p$ value and confidence interval. Declaration of conflict of interest was done in most studies and it was declared as: "no conflict of interest". Only one study in 2015, conflict of interest statement said "None declared".

\section{Table 5: Subgroup analysis of randomized controlled} trials.

\begin{tabular}{|lll|}
\hline Checklist for RCT & $\begin{array}{l}2005 \\
\mathbf{n} 1=1\end{array}$ & $\begin{array}{l}2015 \\
\mathbf{n} 2=6\end{array}$ \\
\hline $\begin{array}{l}\text { The title clearly state that the } \\
\text { study is a "Randomized } \\
\text { controlled trial"? }\end{array}$ & 0 & $2(33.33 \%)$ \\
\hline $\begin{array}{l}\text { Method of randomization } \\
\text { mentioned }\end{array}$ & 0 & $3(50 \%)$ \\
\hline Allocation concealment done & 0 & $1(16.66 \%)$ \\
\hline Blinding done & 0 & $3(50 \%)$ \\
\hline CONSORT flow diagram given & 0 & $2(33.33 \%)$ \\
\hline Trial registered & 0 & $1(16.66 \%)$ \\
\hline
\end{tabular}

As seen from Table 5, subgroup analyses of randomized controlled trials (RCTs) were done and it was found that there were 6 RCTs in 2015 while there was only 1 RCT in 2005. There were 6 checklist points, and none of those were fulfilled by the trial published in 2005. In 2015, 2 $(33.33 \%)$ of studies stated that the study was an RCT in the title, $3(50 \%)$ mentioned the method of randomization, $1(16.66 \%)$ study mentioned that allocation concealment was done, blinding was done in $3(50 \%)$ studies, CONSORT flow chart to indicate the flow of participants was shown in $2(33.33 \%)$ studies and 1 (16.66\%) of the trials was registered in a trial registry.

\section{DISCUSSION}

Research at least to some extent today is a result of "publish or perish "attitude. Organizations consider research publications as a yardstick before offering increments and promotions to faculty members. ${ }^{5}$ The word publication here refers to only research papers and review articles, educational forums and case reports are not considered at par with original research articles. This might have reflected as an increase in proportion of research articles published in 2015 as compared to 2005 (Figure 1) when these guidelines were more obscure.

Ramifications of pharmacological research have increased to include clinical trials, observational studies on clinical pharmacology and others like educational research as compared to a decade ago when pharmacology was more restricted to preclinical studies. This might have resulted in increased publications of research involving human beings in 2015 as compared to 2005 (Table 1). Similar studies conducted in other countries like China have shown increase in clinical research over the decade. ${ }^{6}$ Stringent guidelines of CPCSEA, (Committee for the purpose of control and supervision of experiments on animals) requirement of a registered animal handling facility and Animal ethics committee might have further restricted animal experimentation leading to the current picture.

There is always considerable lag period for translation of plant products into medicinal products. This shortcoming may be overcome by screening of known drugs whose preclinical and basic pharmacokinetics and safety data are already available. Thus, during recent years, focus seems to have shifted from using plant products to approved drugs as active principles and this would hopefully ease early translation of theoretical hypothesis to medications for patients. This possibly explains the higher utilization of drugs as active principle in research studies in 2015 as compared to plant products earlier (Table 2).

Detailed reporting of methodological elements in any research study is the key to its completeness and helps in critical appraisal of current research study and reproducibility of study results in future studies. The checklist used for methodological appraisal during the current study considered minimal requirement standards for any study to be reported. A clear statement of study objectives is very important to see if the study has preceded in the right direction, has it chosen the right design and statistical methods thereof. All published studies had a clear statement in this regard and might reflect the thoroughness of the editorial policy and the adherence of authors to the instructions given.

In order to ensure ethical conduct of research, it has been made mandatory by both CPCSEA and ICMR (Indian Council of Medical Research) to obtain approval from either the animal ethics committee in case of animal studies or Institutional ethics committee in case of studies involving human beings. If the study happens to be the one with less potential for ethical issues, a waiver statement has to be mentioned with reason for waiver. In the present study, the statement of approval by respective 
ethics committees reduced from $88 \%$ in 2005 to $86.56 \%$ in 2015. In the studies which did not mention approval, it is not clear weather approval was not obtained or the authors failed to mention it. The present study shows adherence to ethical issues to a greater extent as compared to studies conducted on other Indian journals where reporting on such matters was as low as $24 \% .^{7}$ This might reflect higher awareness regarding ethical issues amongst the pharmacologists.

Study design was clearly stated in $62.68 \%$ of studies in 2015 and this increase was tremendous as compared to 2005 where only $24 \%$ mentioned the study design. Way back in 2005, most studies were animal experiments and experimental in nature. Many of these failed to mention study design in the methodology and it was to be assumed to be experimental. These findings are consistent with a recent study conducted in 2015 which concludes that Indian Medical literature has made significant progress with respect to study design. ${ }^{8}$

Size of the sample used and justification for this is a very important statistical parameter to draw inference from the results. Many studies with low sample size may give insignificant results only due to the low sample used and does not necessarily mean a negative result. This could lead to inadvertent discard of effective strategies. Although sample size was mentioned, no justification for the size of sample used was provided in any of the studies in 2005. In 2015, 4\% studies justified sample size based on expected effect size or power of the study. This result is similar to a study reported in the Indian journal of Psychiatry where only 1 study mentioned sample size calculation. ${ }^{9}$ Considering this small fraction, we consider this area as a scope for immense improvement.

Conflict of issues was declared in almost all studies published and in this respect, studies included seemed to have fared very well compared to other studies with respect to conflict of interest issues. ${ }^{10}$

The thumb rule for all randomized controlled trials is to state the method of randomization, and to have a method for allocation concealment irrespective of blinding to eliminate selection bias in RCTs. A subgroup comparative analysis of RCTs in our study as well as other studies performing critical appraisal of RCTs have shown very poor performance of published studies with respect to reporting of these methodological issues, despite some improvement in 2015 as compared to 2005. ${ }^{11}$ A CONSORT flow diagram to show the patient enrolment and accountability is important to critically appraise any RCT for its true scientific validity. However, all elements of CONSORT are still far from being optimally implemented. ${ }^{12,13}$

To conclude, trend in 2015 has changed over a decade and currently, it points towards a hike in publishing full length research papers, studies involving human beings and use of drugs as active principles both in human and animal studies. Focus on area of research seems to have shifted from inflammation and wound healing to central nervous system. With respect to standard of reporting, albeit some improvement in the studies published in 2015, some missing links still exist. As in the other countries, biomedical literature in India seems to have proliferated as a matter of quantity, but quality wise, there is scope for improvement in terms of report of study designs, justification of sample size and adherence to CONSORT statement while reporting results of randomised controlled trials. $^{14}$

\section{ACKNOWLEDGEMENTS}

We sincerely thank the Librarian and staff of central library of GMC, Miraj, India for their co-operation during the study.

\section{Funding: No funding sources \\ Conflict of interest: None declared \\ Ethical approval: Not required}

\section{REFERENCES}

1. Prathap T, Aneesh TG, Richard K, Jabez PB. Reporting of methods was better in the clinical trials registry-India than in Indian journal publications. Journal of Clinical Epidemiology. 2013;66(1):10-22.

2. Strech D, Soltmann B, Weikert B, Bauer M, Pfennig A. Quality of reporting of randomized controlled trials of pharmacologic treatment of bipolar disorders: a systematic review. J Clin Psychiatry. 2011;72(9):1214-21.

3. Charan J, Chaudhari M, Jackson R, Mhaskar R, Reljic T, Kumar A. Comparison of methodological quality of positive versus negative comparative studies published in Indian medical journals: a systematic review BMJ Open. 2015;5(6):e007853.

4. Kannan S, Deshpande SP, Gogtay NJ, Thatte UM. Policy of reviewing statistics in Indian medical and surgical journals. J Pharmacol Pharmacother. 2013;4(2):139-40.

5. Seema R, Sanjay M. Publish or perish: where are we heading? J Res Med Sci. 2014;19(2):87-9.

6. Jin Z, Yu D, Zhang L, Meng H, Lu J, Gao Q, et al. A retrospective survey of research design and statistical analyses in selected Chinese medical journals in 1998 and 2008. PLoS One. 2010;5(5):e10822.

7. Mahesh NB, Supriya SB, Renuka PM. Ethics reporting practices in clinical research publications: a review of four Indian journals. Perspect Clin Res. 2014;5:129-33.

8. Hassan S, Yellur R, Subramani P, Adiga P, Gokhale M, Iyer MS, et al. Research design and statistical methods in Indian Medical Journals: a retrospective survey. PLoS One. 2015;10(4):e0121268.

9. Charan J, Saxena D, Yadav P, Kantharia ND. Quality of antidepressant drugs research articles published in Indian medical journals. Indian $\mathrm{J}$ Psychol Med. 2011;33(2):141-4. 
10. Qureshi J, Sud A, Vakil N. Funding source and conflict of interest disclosures by authors and editors in gastroenterology specialty journals revisited. Aliment Pharmacol Ther. 2012;35(6):690-5.

11. Julie P, An-Wen C, Asbjørn H, Elisabeth F, Douglas GA, Peter CG. Comparison of descriptions of allocation concealment in trial protocols and the published reports: cohort study BMJ. 2005;330:1049.

12. Turner L, Shamseer L, Altman DG, Weeks L, Peters $\mathrm{J}$, Kober T, et al. Consolidated standards of reporting trials (CONSORT) and the completeness of reporting of randomized controlled trials (RCTs) published in medical journals. Cochrane Database Syst Rev. 2012;11:MR000030.
13. Can OS, Yilmaz AA, Hasdogan M, Alkaya F, Turhan $\mathrm{SC}$, Can MF, et al. Has the quality of abstracts for randomized controlled trials improved since the release of consolidated standards of reporting trial guideline for abstract reporting? A survey of four high-profile anesthesia journals. Eur J Anaesthesiol. 2011;28(7):485-92.

14. Reema BA, Muaz AM, Reem EH, Razan HK, Ranim AC, Tehreem AK, et al. Comparative analysis of quantity and quality of biomedical publications in Gulf Cooperation Council countries from 2011-2013. Saudi Med J. 2015;36(9):1103-9.

Cite this article as: Murthy MB, Murthy BK, Burute SR, Patil PT, Ramanand SJ. Changing trends with respect to standard of methodological reporting and type of research published in a pharmacology journal over a decade: a descriptive study. Int J Basic Clin Pharmacol 2016;5:1331-6. 